\title{
Analysis of seafloor seismograms of the 2003 Tokachi-Oki earthquake sequence for earthquake early warning
}

\author{
Jeffrey J. McGuire, ${ }^{1}$ Frederik J. Simons, ${ }^{2}$ and John A. Collins ${ }^{1}$ \\ Received 21 March 2008; revised 3 June 2008; accepted 6 June 2008; published 31 July 2008.
}

[1] Earthquake Early Warning (EEW) algorithms estimate the magnitude of an underway rupture from the first few seconds of the $P$-wave to allow hazard assessment and mitigation before the $S$-wave arrival. Many large subductionzone earthquakes initiate $50-150 \mathrm{~km}$ offshore, potentially allowing seafloor instruments sufficient time to identify large ruptures before the $S$-waves reach land. We tested an EEW algorithm using accelerograms recorded offshore Hokkaido in the region of the $2003 \mathrm{M}_{\mathrm{w}} 8.1$ Tokachi-Oki earthquake and its aftershocks. A wavelet transform of the first $\sim 4 \mathrm{~s}$ of the $P$-wave concentrates information about earthquake magnitude from both waveform amplitude and frequency content. We find that wavelets with support of a few seconds provide discriminants for EEW that are both accurate enough to be useful and superior to peak acceleration or peak velocity. Additionally, we observe a scaling of wavelet coefficient magnitude above $\mathrm{M}_{\mathrm{w}} 6.0$ indicating that, at least for the mainshock $\left(M_{w} 8.1\right)$ and largest aftershock $\left(M_{w} 7.1\right)$, the final size of a rupture could have been estimated from the initial portion of the seismogram. Citation: McGuire, J. J., F. J. Simons, and J. A. Collins (2008), Analysis of seafloor seismograms of the 2003 Tokachi-Oki earthquake sequence for earthquake early warning, Geophys. Res. Lett., 35, L14310, doi:10.1029/2008GL033986.

\section{Introduction}

[2] Earthquake Early Warning (EEW) algorithms attempt to estimate the magnitude of an underway rupture from the first few seconds of the incoming $P$-wave, so that hazard mitigation can occur before the arrival of $S$-waves. For faults in continental crust, this requires making a magnitude estimate from only $2-3 \mathrm{~s}$ of $P$-wave data [Allen and Kanamori, 2003; Wu and Zhao, 2006]. Owing to the increase in earthquake duration with magnitude, if all earthquakes initiated in the same manner, there should be no difference between the first $3 \mathrm{~s}$ of a relatively minor $\mathrm{M}_{\mathrm{w}} 5.5$ and a devastating $\mathrm{M}_{\mathrm{w}}$ 8. Yet, EEW algorithms are gaining increasing use and several studies have presented evidence that reliable discriminants between damaging and non-damaging earthquakes can be derived from the initial portion of the $P$-wave [Allen and Kanamori, 2003; Olson and Allen, 2005; Wu and Zhao, 2006; Zollo et al., 2006, 2007]. Owing to the limited number of large $\left(M_{\mathrm{w}} \geq 7\right)$

\footnotetext{
${ }^{1}$ Department of Geology and Geophysics, Woods Hole Oceanographic Institution, Woods Hole, Massachusetts, USA.

${ }^{2}$ Department of Geosciences, Princeton University, Princeton, New Jersey, USA.
}

Copyright 2008 by the American Geophysical Union. 0094-8276/08/2008GL033986\$05.00 earthquakes that have been recorded by modern seismic arrays, there is considerable debate about the ability of these techniques to sense any magnitude scaling above $\mathrm{M}_{\mathrm{w}} \geq 5.5$ [Rydelek and Horiuchi, 2005; Rydelek et al., 2007; Zollo et al., 2006, 2007]. This issue is critically important for both hazard applications and for understanding earthquake nucleation. Many of the methods that have demonstrated scaling behavior extending to $M_{w}>6$ utilized estimates of the frequency (rather than amplitude) of the initial arrival, with relatively low-frequency energy indicating an impending large rupture [Kanamori, 2005; Olson and Allen, 2005]. This observation implies that large earthquakes are more likely when slip initiates within a spatially extended nucleation zone and/or a high stress drop. Currently this debate is limited by a lack of high-quality datasets for $\mathrm{M}_{\mathrm{w}} \geq$ 7 earthquakes.

[3] Subduction-zone thrust faults present favorable sites for EEW of great $\left(\mathrm{M}_{\mathrm{w}} \geq 8\right)$ earthquakes because their seismogenic zones are located almost entirely offshore. Thus, the time between when a large subduction-zone thrust event initiates and when the $S$-waves cause damage (onshore) is much longer than in continental EEW applications. Moreover, since these faults generate the largest ruptures on Earth, they present a natural target for studying the scaling of earthquake nucleation. The $2003 \mathrm{M}_{\mathrm{w}}$ 8.1 Tokachi-Oki earthquake was the first great subduction zone event to be captured by an array of ocean bottom seismometers (OBS) in its epicentral region (Figure 1). A cabled array of strongmotion OBS, deployed in the rupture-zone region by JAMSTEC [Mikada et al., 2006; Watanabe et al., 2006], provided the first high-quality dataset for studying EEW algorithms in a subduction environment.

\section{Data}

[4] We utilize seismograms from two accelerometers (station codes OBS1 and OBS2) of the JAMSTEC Kushiro cabled observatory (http://www.jamstec.go.jp/scdc/top e.html) located above the shallow portion of the seismogenic zone (Figure 1). To ensure that the $P$-waveforms we analyzed were free of interference from surface reflections, we only utilized the two deepest ( $2500 \mathrm{~m}$ depth) JAMSTEC stations and limited our analysis to the first $\sim 4 \mathrm{~s}$ of the $P$-wave arrival. We analyzed the high-gain vertical component of acceleration at both stations for all events - except for the mainshock, for which we had to analyze the raw (i.e. unrotated but nearly vertical) "Y component" low-gain channel due to clipping of the high-gain channels and errors in the archived low-gain vertical component (K. Obana, personal communication, 2007). We utilized 43 accelerograms from $4.0 \leq \mathrm{M}_{\mathrm{w}} \leq 8.1$ shallow earthquakes (FNET centroid depths $\leq 40 \mathrm{~km}$ ) at epicentral distances between 15 


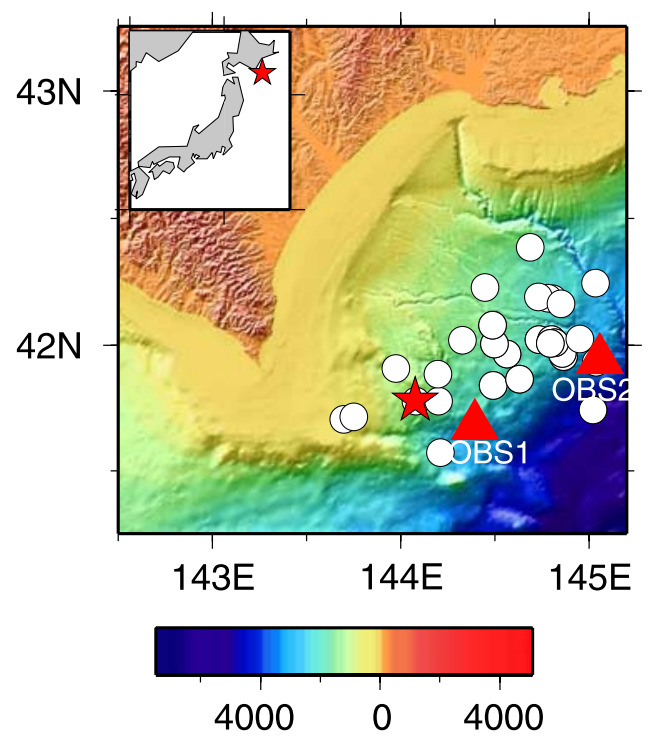

Figure 1. Map of the source area of the $2003 \mathrm{M}_{\mathrm{w}} 8.1$ Tokachi-Oki earthquake. Colors indicate seafloor depth and topography in meters [Kisimoto, 2000]. The locations of the JAMSTEC cabled accelerometers OBS1 and OBS2 (red triangles), the mainshock epicenter (red star), and the aftershocks utilized in this study (white circles) are shown. Inset shows the earthquake location (star) within Japan.

and $60 \mathrm{~km}$ from either station to avoid interference from the $S$ and $P_{\mathrm{n}}$ phases in the first $\sim 4 \mathrm{~s}$. A short-term/long-term average (STA/LTA) detector was used to pick the $P$-wave arrival of each event and a 512 sample (5.12 s) window was extracted that extended from $\sim 1 \mathrm{~s}$ before to $\sim 4 \mathrm{~s}$ after the trigger (see Figure 2). The seismograms were then integrated to velocity using the trapezoidal algorithm.

\section{Wavelet Analysis}

[5] Wavelet analysis in an EEW context seeks to exploit the expected changes in both amplitude and period of the initial $P$-waveform with increasing earthquake magnitude. Numerous studies of earthquake corner frequency have demonstrated that magnitude information can be extracted both from the frequency band concentrating most energy as well as form the low-frequency amplitude of the $P$-wave. Thus, information on event magnitude should be contained in the portion of the seismograms we analyze for earth-

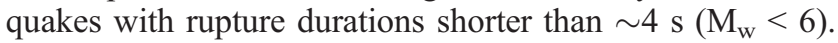
Wavelet expansions combine information about frequency, time, and amplitude into scale-dependent wavelet coefficients, making them intrinsically suitable for EEW. We follow the approach of Simons et al. [2006] and use a biorthogonal wavelet basis [Cohen et al., 1992] with 2 and 4 vanishing moments for the primal and dual wavelets, respectively. The wavelet coefficients are calculated from the velocity seismograms (of length $512=2^{9}$ samples) at 9 scales on a dyadic grid (Figure 2). Like Simons et al. [2006], we used the "lifting" implementation of the discrete-wavelet transform. No boundary corrections were applied. Unlike Simons et al. [2006], we did not threshold because of our prior knowledge that the $P$-wave arrival is contained within the data window. We take the coefficient with the largest absolute value at a particular scale for each waveform as a potential indicator of magnitude. Figure 2 demonstrates that at low scales $(1$ to $\sim 6)$ for small earthquakes, the largest-amplitude coefficients are typically found near the $P$-wave arrival. However, for larger earthquakes and
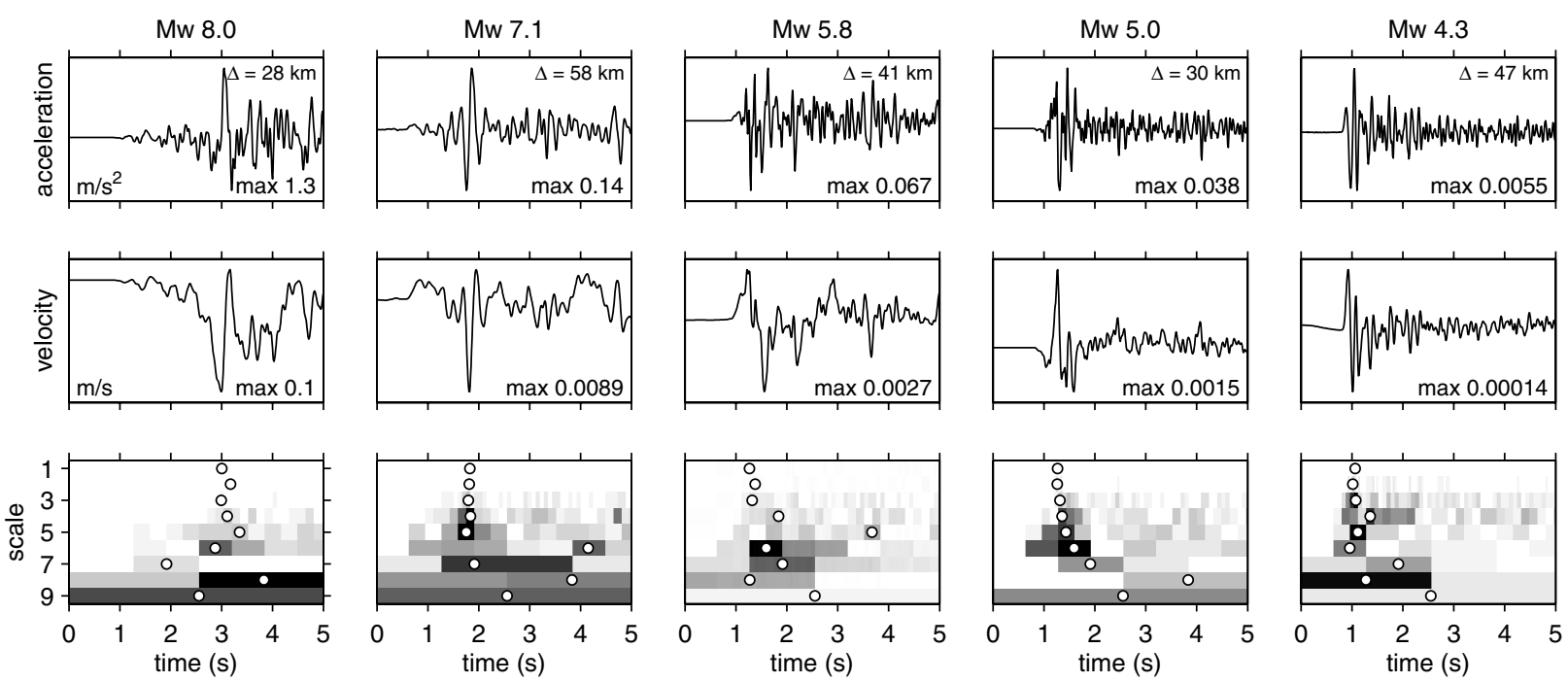

Figure 2. Examples of seismograms and wavelet analysis for 5 earthquakes. The top plots show the 512-sample accelerogram extracted from the raw time series using the STA/LTA trigger. Each trace is labeled with its distance from the epicenter in $\mathrm{km}$ and its maximum amplitude in $\mathrm{m} / \mathrm{s}^{2}$. The middle plots show the same trace integrated to velocity. The bottom plots show the absolute value of the wavelet coefficients at each of the nine scales (darker shades correspond to larger amplitudes) derived from the transformation of the velocity seismograms in the middle plots. The grayscale is the same for all scales within a given plot. At the largest scale (9) equivalent to the entire duration of the window, only one coefficient is calculated. The white circles denote the interval with the largest-amplitude coefficient at a given scale. 

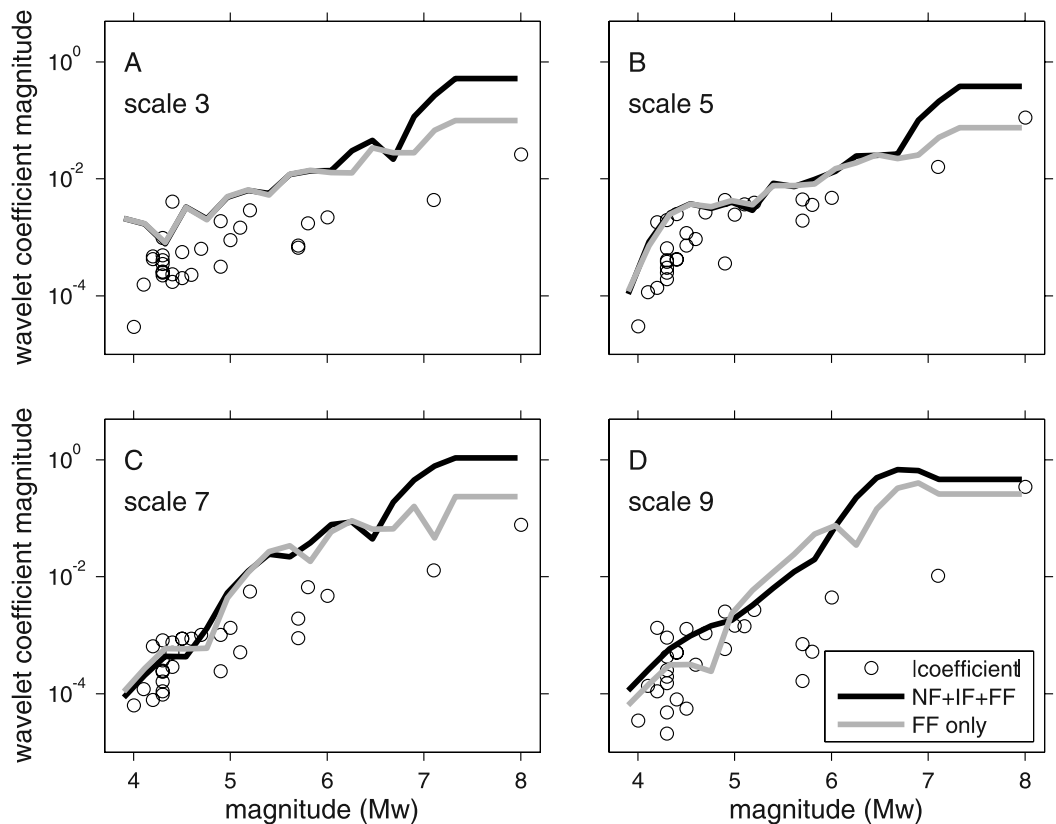

Figure 3. Comparison of peak amplitude of the wavelet coefficients at scales (a) 3, (b) 5, (c) 7, and (d) 9 (white circles) with the earthquake $M_{w}$ estimate. The gray and black lines denote the coefficient values resulting from a wavelet transform of the velocity seismograms expected for the Sato and Hirasawa (SH) source model for a stress drop of $10 \mathrm{MPa}$. At this large stress drop, there is a difference in the first $4 \mathrm{~s}$ of the seismogram between $\mathrm{M}_{\mathrm{w}} 7.1$ and $\mathrm{M}_{\mathrm{w}}$ 8.1, at values of stress drop below $5 \mathrm{MPa}$ there would be no difference in the wavelet coefficients above $\mathrm{M}_{\mathrm{w}} 7$. The black lines include near and intermediate-field terms [Aki and Richards, 2002, equation (4.32)], while the gray line includes only the far-field term. The SH model used a $P$-wave velocity of $6 \mathrm{~km} / \mathrm{s}$, a rupture velocity of $2.5 \mathrm{~km} / \mathrm{s}$, a epicentral distance of $20 \mathrm{~km}$, and a shear modulus of $3 \times 10^{9}$, and a ray takeoff angle $\theta=60^{\circ}$. To scale for propagation effects, the SH curves have been pinned to the median value of the observed coefficient magnitudes at $\mathrm{M}_{\mathrm{w}}$ 4.3.

at larger scales (i.e. lower frequencies), the largest coefficient often occurs later in the arrival, corresponding to large bursts of energy. Furthermore, there is a tendency for the largest-scale (7-9) coefficients to increase in amplitude as earthquake magnitude increases. This pattern appears representative of the Tokachi-Oki dataset and suggests that the largest-scale coefficients, which are derived from $3-5 \mathrm{~s}$ of velocity data, should provide an effective EEW discriminant.

[6] We now test whether the entire Tokachi-Oki dataset demonstrates a strong correlation between the magnitude of the wavelet coefficients and earthquake moment in a manner that would allow potentially damaging $M_{w} \geq 6$ earthquakes to be differentiated from smaller events. Figures $3 \mathrm{a}-$ $3 \mathrm{~d}$ show the variation in the maximum absolute value of the coefficients at scales $3,5,7$, and 9 . The values have not been corrected for wave propagation or epicentral distance, because these parameters would not be known reliably in real-time for offshore environments. The lack of a correction for epicentral distance is likely to account for much of the scatter at a particular magnitude level [Wu and Zhao, 2006; Zollo et al., 2006, 2007]. Despite this, it is clear that the $\mathrm{M}_{\mathrm{w}} \geq 7$ earthquakes have the largest coefficient magnitudes at every scale, and that the separation between the $\mathrm{M}_{\mathrm{w}} \sim 4-5$ and the $\mathrm{M}_{\mathrm{w}}$ 7-8 events increases with scale. Thus, the most accurate discriminants on earthquake size are the coefficients at scales 8 and 9 , which are only sensitive to low-frequency information. We repeated the above analysis using the acceleration records, which resulted in very similar patterns as those obtained from the velocity seismograms.

[7] To evaluate the cause of the increase in coefficient amplitude with earthquake magnitude, we compare our measurements to wavelet coefficients calculated for the Sato and Hirasawa (SH) kinematic source model [Sato and Hirasawa, 1973; Aki and Richards, 2002] of an expanding circular rupture with a constant stress drop. We calculated the vertical-component seismograms for a rupture with a stress drop of $10 \mathrm{MPa}$ including the near-field (NF), intermediate-field (IF), and far-field (FF) terms in an elastic whole space [Aki and Richards, 2002, equation (4.32)]. The resulting displacement seismograms were differentiated and then processed using the same wavelet decomposition as the data. We processed seismograms containing all three terms as well as ones containing only the far-field term. We did not correct the SH seismograms for wave propagation effects (e.g. attenuation) so they represent a best-case scenario for the amount of magnitude information likely to be available in the first $4 \mathrm{~s}$ of the $P$ wave arrivals. To allow the SH coefficients to be plotted on the same scale as the data, we normalized their amplitude at $\mathrm{M}_{\mathrm{w}} 4.3$ for each scale to equal the median of the coefficient values at that scale derived from $\mathrm{M}_{\mathrm{w}} 4.3$ earthquakes. The SH model curves in Figure 3 demonstrate that scaling of the coefficients between $\mathrm{M}_{\mathrm{w}} 4$ and $\mathrm{M}_{\mathrm{w}} \sim 6-7$ should be expected due to the $4 \mathrm{~s}$ duration of our seismogram window. The upper end of the scaling region depends on the assumed 


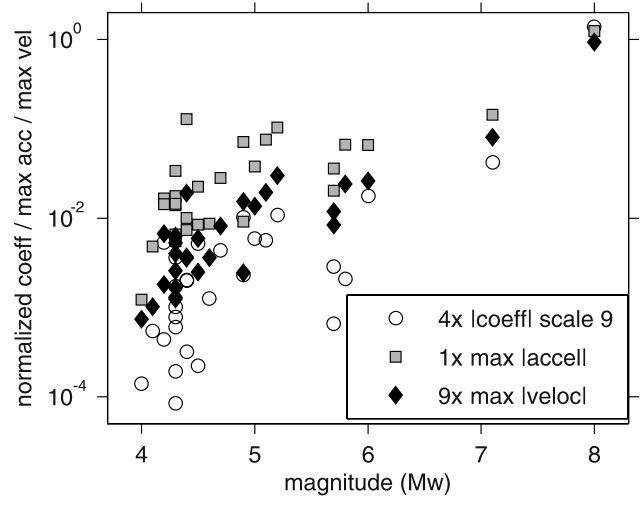

Figure 4. Comparison of magnitude estimates. Peak absolute value of acceleration (gray squares), peak absolute value of velocity (black diamonds) calculated from the first 4 s of the $P$-wave and the wavelet coefficient at the 9th scale (open circles) have all been normalized to 1 for the mainshock.

stress drop and would be $\mathrm{M}_{\mathrm{w}} \sim 6$ for a $1 \mathrm{MPa}$ stress drop. While the SH model is simplistic, it demonstrates that even for high (10 MPa) stress drops, we should not expect a larger coefficient value for the mainshock $\left(\mathrm{M}_{\mathrm{w}} 8.1\right)$ than the largest aftershock $\left(M_{w} 7.1\right)$. This theoretical result is intuitive since both the $M_{w} 7.1$ and $M_{w} 8.1$ earthquakes had durations significantly longer than $4 \mathrm{~s}$. However, the observed values continue on the same scaling trend well beyond $\mathrm{M}_{\mathrm{w}}$ 6. A similar observation for the mainshock was made by Kanamori [2005] using the predominant period as a diagnostic of earthquake magnitude. One potential mechanism for generating the unusually large coefficient values for the $M_{w} 8.1$ mainshock would be if its seismograms contained significant contributions from NF and IF terms. The black curves in Figure 3 demonstrate that seismograms containing those will produce larger coefficients than those that do not. Owing to the epicentral distances and magnitudes of the various events, only the $\mathrm{M}_{\mathrm{w}} 8.1$ mainshock in Figure 3 is likely to have NF and IF terms contributing to its seismogram.

\section{Discussion}

[8] From an earthquake early warning (EEW) perspective, the best metric is the one with the best-resolved difference between events that cause widespread damage $\left(\mathrm{M}_{\mathrm{w}} \geq 6\right)$ and those that don't $\left(\mathrm{M}_{\mathrm{w}}<6\right)$. Figure 4 compares the dynamic range of the wavelet coefficients at scale 9 with two common observables of the same data: peak absolute value of velocity and peak absolute value of acceleration. There is a clear trend of greater separation between small and large events as one switches from peak acceleration to peak velocity to the wavelet coefficients. This progression demonstrates the need to consider both signal amplitude and frequency in an EEW metric. The largest-scale wavelet coefficients vary by four orders of magnitude between $M_{w}$ 4.0 and $\mathrm{M}_{\mathrm{w}} 8.1$ and hence provide the best diagnostic for identifying damaging earthquakes.

[9] The scaling of the wavelet coefficients across the entire earthquake size range (Figure 3 ) is a surprising result that may imply that the final magnitude of the rupture depends on the properties of the nucleation zone. The mainshock lasted about $50 \mathrm{~s}$ and most of the moment release occurred well downdip of the epicentral region [Yagi, 2004]. Thus, the large amplitude of the wavelet coefficients for the mainshock $P$-wave (Figure 3 ) does not reflect the majority of the moment release but rather the properties of the epicentral region compared to the rupture zones of the aftershocks. Three factors may contribute to this difference. First, the greater propagation distance for the $\mathrm{M}_{\mathrm{w}} 7.1(58 \mathrm{~km})$ to the OBS than for the $\mathrm{M}_{\mathrm{w}} 8.1(28 \mathrm{~km})$ leads to a smaller coefficient for the $\mathrm{M}_{\mathrm{w}} 7.1$ owing to geometrical spreading and attenuation. However, it is also evident from the velocity waveforms in Figure 2 that the initial portion of the $P$-wave of the $\mathrm{M}_{\mathrm{w}} 8.1$ events was enriched in lowfrequency energy relative to the $M_{w} 7.1$ event, despite experiencing less attenuation. This is reflected in the highest-amplitude coefficient for the $\mathrm{M}_{\mathrm{w}} 7.1$ event occurring at scale 5 while for the $M_{w} 8.1$ the highest amplitude occurs at scale 8 (Figure 2). One explanation for the enriched lowfrequency content of the $\mathrm{M}_{\mathrm{w}} 8.1$ is that its seismogram contains near-field (NF) and intermediate-field (IF) terms, as this station may be within about one fault length of the source region, given location uncertainties. NF and IF terms are proportional to the moment release history rather than the moment-rate history that specifies the ordinary far-field $P$-waveforms, making them inherently lower frequency. Moreover, they do not become a significant contribution to the seismogram until the earthquake magnitude is fairly large. Thus, NF and IF terms may preferentially contribute to the increase in coefficient magnitude between the $\mathrm{M}_{\mathrm{w}} 7.1$ and $\mathrm{M}_{\mathrm{w}} 8.1$ earthquakes.

[10] A third contribution to the large-amplitude wavelet coefficients may result from an unusually large stress drop in the epicentral region of the mainshock that would generate higher-amplitude waveforms during the first $4 \mathrm{~s}$ of rupture than in ordinary events. Sato and Mori [2006] found that the first $0.1 \mathrm{~s}$ of the mainshock rupture was fairly ordinary with a low ( 1 MPa) stress drop, but Yagi’s [2004] finite source inversion, which did not utilize the JAMSTEC OBS data, found that the mainshock began with a very high-stress-drop ( $\sim 10 \mathrm{MPa})$ subevent. This is surprising in that the updip edge of the seismogenic zone is thought to represent the trenchward boundary of the zone in which the rock is competent enough to support the stress levels necessary for earthquake rupture [Moore and Saffer, 2001]. However, if the rupture did begin with a high stress-drop subevent, it would be expected to have a greater chance of leading to a large rupture owing to the greater stress concentration at the rupture front [Yamada and Heaton, 2007]. Thus, it may be prudent to site seafloor instruments for EEW near locations of unusually competent (high-velocity) rock. Overall, the large amplitude of the $\mathrm{M}_{\mathrm{w}}$ 8.1 coefficient relative to the $M_{w} 7.1$ appears to imply an unusual nucleation process for the mainshock, but this may be specific to the Tokachi-Oki sequence rather than a general feature of large earthquakes.

\section{Conclusions}

[11] The 2003 Tokachi-Oki mainshock initiated 65-90 $\mathrm{km}$ from the coastal region most directly affected by the strong shaking and tsunami, a distance that allows sufficient 
time for seafloor-based EEW systems to communicate with shore. The first $S$-waves reached shore between $20-30$ s after the rupture began while the $P$-wave arrived at OBS1 $8 \mathrm{~s}$ after the rupture began. Thus, the data needed to calculate the wavelet coefficients in Figure 3 was available $8-18 \mathrm{~s}$ before the first $S$-waves reached land. Moreover, the rupture itself lasted almost $50 \mathrm{~s}$ with the largest pulse of moment release occurring about $20-30 \mathrm{~s}$ into the rupture [Yagi, $2004]$, so the primary damage from the main $S$-wave pulse began $>25 \mathrm{~s}$ after the initial magnitude estimate was available on the seafloor. The JAMSTEC OBS had realtime telemetry via a submarine cable and thus only a $\sim 1 \mathrm{~s}$ transmission latency. While cabled observatories are ideal, very few have been installed due to their cost. A potential, cheaper solution is to link the OBS to a moored buoy via an acoustic modem and then to shore via a satellite link. This type of system had about a one-minute "seafloor to shore" transmission time in a deployment off Cascadia [Frye et al., 2006], the majority of which was spent reestablishing the communications channels for each transmission. The data transmission time could be as little as $\sim 10 \mathrm{~s}$ if both the acoustic and satellite communications channels were continuously open.

[12] Perhaps the strongest argument for establishing seafloor based EEW observatories in subduction zones is simply the unique sensitivity of such data to earthquake source properties. Near-source seismograms are not contaminated with the arrivals of later phases, particularly refracted phases that can distort the waveform's frequency content. Thus, EEW metrics will be more accurately determined from local OBS data than regional (on land) data. Moreover, these recordings can include the near and intermediate-field terms, and hence have a greater sensitivity to magnitude (Figure 3). Any seafloor observatory could also include a pressure sensor capable of detecting vertical deformation on the order of $\sim 10 \mathrm{~cm}$ or greater [Tamaki et al., 2002]. Since uplift of the seafloor in the source region is the source term for tsunami generation, this fundamental data type would greatly improve real-time tsunami forecasts for the regions immediately adjacent to the rupture zone. Owing to the greater travel time of tsunamis such data could easily be communicated to shore in time to affect warning decisions.

[13] Acknowledgments. We thank K. Obana and T. Watanabe for help with the JAMSTEC data. M. Yamada provided insightful suggestions on the influence of the near-field term. We thank an anonymous reviewer for suggesting several clarifications. This work was supported by the Deep Ocean Exploration Institute at WHOI.

\section{References}

Aki, K., and P. G. Richards (2002), Quantitative Seismology, 2nd ed., 704 pp., Univ. Sci., Sausalito, Calif.
Allen, R. M., and H. Kanamori (2003), The potential for earthquake early warning in southern California, Science, 300(5620), 786-789, doi:10.1126/ science. 1080912.

Cohen, A., et al. (1992), Biorthogonal bases of compactly supported wavelets, Commun. Pure Appl. Math., 45, 485-560.

Frye, D., L. Freitag, R. Detrick, J. Collins, J. R. Delaney, D. Kelley, A. Labonte, and K. M. Brown (2006), An acoustically linked moored buoy ocean observatory, Eos Trans. $A G U, 87,213$.

Kanamori, H. (2005), Real-time seismology and earthquake damage mitigation, Annu. Rev. Earth Planet. Sci., 33, 195-214.

Kisimoto, K. (2000), Combined bathymetric and topographic mesh data: Japan250m.grd, Geol. Surv. Jpn. Open File Rep. 353, Natl. Inst. of Adv. Ind. Sci. and Technol., Tsukuba, Japan.

Mikada, H., et al. (2006), New discoveries in dynamics of an M8 earthquake-phenomena and their implications from the 2003 Tokachi-oki earthquake using a long term monitoring cabled observatory, Tectonophysics, 426, 95-105.

Moore, J. C., and D. Saffer (2001), Updip limit of the seismogenic zone beneath the accretionary prism of southwest Japan: An effect of diagenetic to low-grade metamorphic processes and increasing effective stress, Geology, 29(2), 183-186.

Olson, E. L., and R. M. Allen (2005), The deterministic nature of earthquake rupture, Nature, 438(7065), 212-215.

Rydelek, P., and S. Horiuchi (2005), Earth science: Is earthquake rupture deterministic?, Nature, 438(7065), 212-215.

Rydelek, P., C. Wu, and S. Horiuchi (2007), Comment on "Earthquake magnitude estimation from peak amplitudes of very early seismic signals on strong motion records" by Aldo Zollo, Maria Lancieri, and Stefan Nielsen, Geophys. Res. Lett., 34, L20302, doi:10.1029/2007GL029387.

Sato, K., and J. Mori (2006), Scaling relationship of initiations for moderate to large earthquakes, J. Geophys. Res., 111, B05306, doi:10.1029/ 2005JB003613.

Sato, T., and T. Hirasawa (1973), Body wave spectra from propagating shear cracks, J. Phys. Earth, 21, 415-431.

Simons, F. J., et al. (2006), Automatic detection and rapid determination of earthquake magnitude by wavelet multiscale analysis of the primary arrival, Earth Planet. Sci. Lett., 250, 214-223, doi:10.1016/j.eps1. 2006.07.039.

Tamaki, T. et al. (2002), Vertical crustal movement on the seafloor detected with differential pressure monitoring, in Underwater Technology, 2002: Proceedings of the 2002 International Symposium on Underwater Technology, pp. 317-319, Inst. of Electr. and Electron. Eng., Piscataway, N. J.

Watanabe, T., et al. (2006), Seismological monitoring on the 2003 TokachiOki earthquake, derived from off Kushiro permanent cabled OBSs and land-based observations, Tectonophysics, 426, 107-118.

Wu, Y.-M., and L. Zhao (2006), Magnitude estimation using the first three seconds P-wave amplitude in earthquake early warning, Geophys. Res. Lett., 33, L16312, doi:10.1029/2006GL026871.

Yagi, Y. (2004), Source rupture process of the 2003 Tokachi-oki earthquake determined by joint inversion of teleseismic body wave and strong ground motion data, Earth Planets Space, 56, 311-316.

Yamada, M., and T. Heaton (2007), Predicting the ultimate size of an earthquake which is still ongoing and its application to earthquake early warning systems, paper presented at Annual Meeting, Seismol. Soc. of Am., Kona, Hawaii.

Zollo, A., M. Lancieri, and S. Nielsen (2006), Earthquake magnitude estimation from peak amplitudes of very early seismic signals on strong motion records, Geophys. Res. Lett., 33, L23312, doi:10.1029/ 2006 GL027795.

Zollo, A., M. Lancieri, and S. Nielsen (2007), Reply to comment by P. Rydelek et al. on "Earthquake magnitude estimation from peak amplitudes of very early seismic signals on strong motion records", Geophys. Res. Lett., 34, L20303, doi:10.1029/2007GL030560.

J. A. Collins and J. J. McGuire, Department of Geology and Geophysics, Woods Hole Oceanographic Institution, Woods Hole, MA 02543, USA. (jmcguire@whoi.edu)

F. J. Simons, Department of Geosciences, Princeton University, Princeton, NJ 08544, USA. 